Savunma Bilimleri Dergisi

The Journal of Defense Sciences

Kasim/Nov 2018, Cilt/Volume 17, Say1/Issue 2.

ISSN (Bas1l1) : 1303-6831 ISSN (Online): 2148-1776

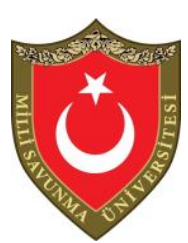

\title{
AISI 10081040 ve 4140 Çeliklerinde Isıl İşlem, Karbon Oranı ve Alaşım Elementlerinin Mikroyapı ve Mekanik Özelliklere Etkisinin İncelenmesi
}

\author{
Ayhan AYTAÇ*, Mehmet Samir IŞIK, Burak ÇANAKÇI, Tekin ÖZDEMİR, \\ Kadir AZTEKİN ve Hüseyin IPEK**
}

$\ddot{O} z$

Bilindiği üzere endüstride kullanılan metal malzemelerin büyük bir bölümünü çelikler oluşturmaktadır. Çelik malzemelerin yoğun kullanılmasının başlıca sebepleri arasında bol miktarda olmaları, ekonomik olarak şekillendirilmeleri ve çok geniş ölçüde mekanik özellik sunabilmeleri yer almaktadır. Çeliklerin temel alaşım elementi karbon (C) olup içerisindeki bileşimine bağlı olarak farklı özellikler gösterirler. Ayrıca, alaşım elementleri de çeliğin mikroyapısında farklılık yaratarak çekme mukavemeti, akma sınırı, darbe dayanımı, süneklik ve işlenebilirlik gibi bir takım mekanik özelliklerini önemli ölçüde etkilemektedir.

Bu çalışmada AISI 1008 ve 1040 çelikleri arasında karbon oranının, AISI 1040 ve 4140 çelikleri arasında da bazı alaşım elementlerinin mikroyapı ve mekanik özellikleri nasıl etkilediği deneysel olarak incelenmiştir. İnceleme sürecinde üç farlı çelik türünden; çekme testi, mikrosertlik testi ve ışık metal mikroskobunda mikroyapı görüntüleme için stok haldeki çeliklerden herhangi bir ısıl işlem yapılmadan numuneler hazırlanmıştır. Çekme testinde ısıl işlemin etkisini görmek amacıyla da ilave numuneler hazırlanmıştır.

Hazırlanan numunelere yük kontrollü çekme testi, mikroVickers sertlik testi ve mikroyap görüntüleme işlemleri gerçekleştirilmiştir. Sonuç olarak; hem karbon oranının hem de alaşım elementlerinin etkisi ile akma ve çekme dayanımının arttlğı, \% uzama ve \% kesit daralması değerlerinin düştüğ̈̈ görülmüştür. Karbon oranı, çekme dayanımında ve \% kesit daralmasında daha etkili iken, alaşım elementleri, akma dayanımı ve \% uzama üzerinde daha etkili olduğu tespit edilmiştir.

Anahtar Kelimeler: AISI 1008, AISI 1040, AISI 4140, Mikroyapı, İçyapı, Mekanik Özellikler.

* Sorumlu Yazar: Dr., Öğretim Görevlisi, Milli Savunma Üniversitesi, Kara Harp Okulu Dekanlığı, Makina Mühendisliği Bölümü, aytac@kho.edu.tr

** Milli Savunma Üniversitesi, Kara Harp Okulu Dekanlığı, Makina Mühendisliği Bölümü. Geliş Tarihi/Received:09.04.2018 Kabul Tarihi/Accepted:04.05.2018 


\title{
Investigation of Microstructure and Mechanical Properties of Heat Treatment, Carbon Ratio and Alloying Elements in AISI 1008, 1040 and 4140 Steels
}

\begin{abstract}
Most of the metal materials used in the industry are made of steel. Among the main reasons for the common use of steel materials are abundance, economical shaping and a wide range of mechanical properties. The basic alloy element of the steels is carbon $(C)$ and shows different properties depending on its composition. In addition, alloying elements significantly affect a number of mechanical properties such as tensile strength, yield strength, impact strength, ductility and machinability by making a difference in the microstructure of the steel.

In this study, the effect of carbon ratio between AISI 1008 and 1040 steel and some alloying elements between AISI 1040 and 4140 steels were investigated experimentally. During the analysis process, three different types of steel; specimens were prepared without any heat treatment of the stock steels for tensile testing, microhardness test and microstructural imaging of the light metal microscope. Samples were also prepared in order to see the effect of heat treatment in the tensile test.

Load-controlled tensile test, microVickers hardness test and microstructure imaging were performed for the prepared samples. As a result; both the carbon ratio and the effect of the alloying elements increase the yield and tensile strength, and the \% elongation and \% section shrinkage values decrease. Carbon ratio is more effective in tensile strength and \% shrinkage, while alloying elements are more effective in yield strength and \% elongation.
\end{abstract}

Keywords: AISI 1008, AISI 1040, AISI 4140, Microstructure, Internal Structure, Mechanical Properties.

\section{Giriş}

Teknolojinin ilerlemesine bağlı olarak yeni imalat ve üretim teknolojileri gelişmekte ve bu teknolojilerin kullanılmasıyla yeni malzeme kompozisyonları 
AISI 10081040 ve 4140 Çeliklerinde Isıl İşlem, Karbon Oranı ve

Alaşım Elementlerinin Mikroyapı ve Mekanik Özelliklere Etkisinin İncelenmesi

ortaya çıkmaktadır. Malzemelerin özelliklerini ve kullanım şartlarını belirleyen en önemli faktörlerden birisi de mekanik özellikleridir. Mekanik özellikler, malzeme seçiminde büyük öneme sahiptir ve çeliklerde mekanik özellikleri arttırmanın en bilinen yolları arasında; karbon oranını arttırmak, alaşımlama yapmak, 1sıl işlem yapmak gibi yöntemler bulunmaktadır. Karbon ve diğer elementlerin, çeliklerin mekanik özelliklerine etkileri üzerine literatürde yer alan birçok araştırma bulunmaktadır.

Demir esaslı alaşımlar olarak bilinen dökme demirler ve çelikler, diğer metal ve alaşımlarına göre daha fazla kullanılmaktadır. Çelik ve dökme demirlerin endüstride yoğun talep görmeleridir. Ayrıca yeryüzünde bol miktarda bulunmaları, cevher halinden ayrıştırılması süreciyle beraber üretiminin göreceli olarak ekonomik olması ve belki de en önemlisi çok geniş bir aralıkta mekanik özelliklere sahip olabilme durumlarına bağlıdır (Callister, 2013). AISI-4140 çeliği, içerdiği $\mathrm{Cr}$ ve Mo alaşım elementleri nedeniyle, su verme 1sıl işlemi sonrasında sert martenzitik bir yapı oluşturabilmesi, mukavemet, süneklilik ve tokluk gibi mekanik özelliklerin bir arada bulunmasına olanak sağlamaktadır. Bu nedenlerden dolayı AISI-4140 çeliği yaygın bir kullanım alanına sahiptir (Avner, 1986:315-336 ve Choo vd., 2000:56-70).

Çeliklerin temel alaşım elementi Karbon (C) olup içerisindeki bileşimine bağlı olarak farklı özellikler gösterirler. Düşük karbonlu çelikler sünektir ve işlenmesi kolaydır. Karbon miktarına bağlı olarak su verme ile sertlikleri artarken işlenebilirlik kabiliyetleri düşer. Karbonun yanısıra çelik içerisinde bulunan diğer alaşım elementleri de çeliğe farklı mekanik özellikler kazandırmaktadır. Alaşım elementleri çeliğin içyapısında farklılık yaratarak çekme mukavemeti, akma sınırı, darbe dayanımı, süneklik ve işlenebilirlik gibi mekanik özelliklerinin değişiminde önemli bir rol oynar (Thelning, K-E., 1984:45-93).

Karbon, çeliğin sertleşmesinde etkili olan elementlerden en önemlisidir. Karbon miktarındaki artış sertlik ve çekme dayanımını pozitif yönde etkiler. Buna karşın, esnekliği, kaynak edilebilme kabiliyetini ve işlenebilirliğini olumsuz yönde etkilemektedir. Ferrit yapı içerisinde karbür fazının oluşumu mukavemeti artırırken sünekliği düşürmektedir ( Krauss ve Grossmann, 1980:5-290, Parrish, 1980: 5270). Karbon içeriği Martensit yap1 sertliğini ve sertleşme özelliklerini etkiler. Karbon içeriği çeliklerin mikroyapı ve mekanik özellikleri üzerinde önemli etkilere 
sahiptir. Farklı karbon içeriğine sahip çelik numuneler, ikili faz bölgesinde farklı sıcaklıklarda 1sıl işleme tabi tutulduğunda, farklı martenzit oranlarına sahip dual fazlı çelikler elde edilmiştir. Artan karbon içeriği ve martenzit hacim oranı sertliği ve mukavemeti artırmaktadır (Valeria vd., 2015:1047-1056).

Demir-Karbon denge diyagramına göre, karbon yüzdesindeki artışın, östenit ve ferrit yapıların bir arada bulunduğu sıcaklık aralığını azalttığı bulunmuştur. $\mathrm{Bu}$ da, yüksek karbon içeriğine sahip malzemelerin 1sıl işlemlerde sıcaklık değişimlerine daha duyarlı olduğunu ifade etmektedir. Ayrıca, S3 ve S4 çeliklerinde artan Mn ve Si içerikleri ikili bölge sıcaklığının üst sınır çizgisini aşağı çekmektedir (Lorusso, 2009, 2011:165-176).

Alaşım elementlerinin çeliğin mekanik özelliklerine belli oranlarda yaptığı pozitif etkiler bilinmektedir (Tablo 1). Mangan (Mn); karbon gibi çeliğin yapısında üretim işlemlerinde yer alan bir elementtir ve çeliğin mukavemetini pozitif yönde arttıran etki gösterir. Ayrıca çeliğin sertleşebilme ve kaynak edilebilirlik kabiliyetlerini de artırır. Krom (Cr); çeliğin sünekliliğini çok düşük bir miktarda azaltmasına sebep olurken dayanıklılığı arttıran bir alaşım elementidir. Molibden (Mo); malzeme yapısında tane büyümesini engeller, sertleşebilme yeteneğini artırır, temperleme gevrekliğini giderir. Silisyum (Si); oksijen giderici olarak kullanılır. Çeliğin akma, çekme dayanımını ve sünekliğini artıır. Çelik yapısındaki silisyum miktarı azaldıkça tufal yapma oranı artar. Kükürt (S); akma ve çekme mukavemetine çok az etkide bulunur. Buna rağmen malzemenin yüzde uzamasına ve tokluğuna etkisi azımsanmayacak kadar fazladır. Malzemenin tokluğuna ve sünek özelliğinin zayıflamasına yol açar. Kaliteli olan ıslah çeliklerinde en yüksek kükürt miktarı \%0.045 iken asal sslah çeliklerinde bu \%0,035'dir. Fosfor (P); çeliklerde olumsuz etkiler yaratan ve içeriğinde bulunması istenilmeyen bir elementtir. Çeliğin sünekliği ve tokluğu üzerinde azımsanmayacak derecede kötü etkiler bıraktığı için yaygın kullanımından bahsedilemez (http://www.atacelik.com/etkileri.html). 
AISI 10081040 ve 4140 Çeliklerinde Isıl İşlem, Karbon Oranı ve

Alaşım Elementlerinin Mikroyapı ve Mekanik Özelliklere Etkisinin İncelenmesi

Tablo 1. Çeliğe alaşım elementlerinin etkileri (http://www.atacelik.com/ etkileri.html)

\begin{tabular}{lccccccccc}
\hline Özellikler/ Alașım Elementleri & C & Mn & Si & Cr & Ni & Mo & W & Co & Al \\
\hline Çekme Mukavemeti & $\downarrow$ & $\perp$ & $\downarrow$ & $\downarrow$ & $\perp$ & $\perp$ & $\downarrow$ & $\downarrow$ & $\downarrow$ \\
Uzama & $\downarrow$ & $\rightarrow$ & $\downarrow$ & $\downarrow$ & + & $\rightarrow$ & $\downarrow$ & $\downarrow$ & $\downarrow$ \\
Kritik Soğuma Hızı & $\downarrow$ & $\downarrow$ & + & $\downarrow$ & $\downarrow$ & $\rightarrow$ & $\rightarrow$ & $\downarrow$ & $\rightarrow$ \\
Sertleșme Derinliği & + & + & + & + & + & + & + & + & $\downarrow$ \\
Sıcakta Mukavemet & + & + & + & + & + & + & + & + & + \\
Meneviş Dayanıklıı̆̆ & $\rightarrow$ & $\rightarrow$ & + & + & $\rightarrow$ & + & + & + & $\rightarrow$ \\
Aşınma Mukavemeti & + & + & + & + & + & + & + & + & $\rightarrow$ \\
Tufallaşmaya Dayanıklılık & $\downarrow$ & $\rightarrow$ & + & + & + & $\downarrow$ & $\rightarrow$ & + & + \\
Talaş Kaldırabilirlik & $\downarrow$ & $\downarrow$ & $\downarrow$ & $\downarrow$ & $\downarrow$ & $\downarrow$ & $\downarrow$ & + & $\rightarrow$ \\
Korozyon Dayanıklıı̆ı & $\downarrow$ & $\rightarrow$ & + & + & + & + & $\rightarrow$ & + & + \\
\hline
\end{tabular}

Çeliklerde alaşım elementleri ile kompozisyona bağlı olarak ikili fazların elde edilmesi ve kaynaklanabilirlik gibi teknolojik özellikleri tanımlanmaya çalışılmaktadır (Maffei vd., 2007:3325-3332). Bugüne kadar çeliğin kompozisyonuna bağlı olarak çok miktarda bilgi üretilmesine rağmen, çeliklerin mekanik özelliklerinin karbon ile evrimi hakkında tartışmalar halen araştırma ve değerlendirme aşamasındadır.

\section{Malzeme ve Metot}

\section{Numunelerin Hazırlanması}

Malzemeler, talaş kaldırma işleminin olumsuz özelliklerinden kaçınmak için üretildikleri çaplarda doğrudan kullanılmıştır. Stok halde bulunan AISI 1008 malzemesinden $14 \mathrm{~mm}$ çapında, AISI 1040 malzemesinden $16 \mathrm{~mm}$ çapında ve AISI 4140 malzemesinden $14 \mathrm{~mm}$ çapında çekme testi, sertlik ölçümü ve mikro yap1 görüntülemesi için numuneler hazırlanmıştır. Ereğli Demir ve Çelik Fab. T.A.Ş. firmasından temin edilen malzemelerin kimyasal bileşimleri Tablo 2'de verilmiştir. 
Tablo 2. Malzemelerin kimyasal bileşimleri (https://www.erdemir.com.tr)

\begin{tabular}{|c|c|c|c|c|c|c|c|}
\hline Malzeme & $\begin{array}{c}\text { Karbon } \\
(\mathrm{C})\end{array}$ & $\begin{array}{c}\text { Mangan } \\
(\mathrm{Mn})\end{array}$ & $\begin{array}{c}\text { Fosfor } \\
(\mathrm{P})\end{array}$ & $\begin{array}{c}\text { Kükürt } \\
(\mathrm{S})\end{array}$ & $\begin{array}{c}\text { Krom } \\
(\mathrm{Cr})\end{array}$ & $\begin{array}{c}\text { Molibden } \\
(\mathrm{Mo})\end{array}$ & $\begin{array}{c}\text { Silisyum } \\
(\mathrm{Si})\end{array}$ \\
\hline $\begin{array}{c}\text { AISI } \\
1008\end{array}$ & $0,02-0,1$ & $\leq 0,5$ & $\leq 0,03$ & $\leq 0,035$ & 0,15 & 0,06 & 0,1 \\
\hline $\begin{array}{c}\text { AISI } \\
1040\end{array}$ & $0,37-0,44$ & $0,6-0,9$ & $\leq 0,03$ & $\leq 0,035$ & - & - & $0,15-0,35$ \\
\hline $\begin{array}{c}\text { AISI } \\
4140\end{array}$ & $0,38-0,43$ & $0,75-1$ & $\leq 0,035$ & $\leq 0,04$ & $0,8-1,1$ & $0,15-0,25$ & $0,15-0,25$ \\
\hline
\end{tabular}

Çekme testi numunelerine normalizasyon ısıl işlemi uygulanmıştır. $\mathrm{Bu}$ uygulama gerçekleştirilirken $845{ }^{\circ} \mathrm{C}$ 'de tavlanan numuneler durgun havada soğumaya bırakılmıştır. Böylelikle malzemelerin üretim aşamasında oluşmuş olabilecek homojensizlikler giderilmiş ve mekanik özellikleri iyileştirilmiştir.

\section{Çekme Testi}

Hazırlanan numunelerin çekme testleri, $500 \mathrm{kN}$ kapasiteli Instron 8803 tek eksenli servohidrolik test sisteminde, $15 \mathrm{kN} /$ dakika hızında yük kontrollü olarak 3'er numune ile gerçekleştirilmiştir. Çekme cihazı yardımıyla malzemelerin; akma gerilmesi, çekme gerilmesi, \% uzama değerleri ve \% kesit daralması değerleri belirlenmiş ve değerlerin ortalamaları hesaplanmıştır.

\section{Sertlik Ölçümü}

Numunelerin sertlik ölçümleri Qness Q10 mikrosertlik test cihazında, mikroVickers yöntemiyle gerçekleştirilmiştir. Test parametreleri olarak HV0,5 yük, 10 saniye ana yükleme değerleri belirlenmiş, iz görüntüleri 40X lens yardımıyla alınmıştır.

\section{Mikroyapı İncelemesi}

3 farklı malzemeden 15 mm kalınlığında numuneler kesilmiş, sıcak bakalit kalıba alınmıştır. Daha sonra zımparalama, parlatma ve Nital-3 kimyasalı ile 
AISI 10081040 ve 4140 Çeliklerinde Isıl İşlem, Karbon Oranı ve

dağlama işlemleri gerçekleştirilmiştir. Hazırlanan numunelerin, Nikon MA200 Işık mikroskobu yardımıyla 100X, 200X, 500X ve 1000X büyütmelerde mikroyapı görüntüleri alınmıştır.

\section{Test Sonuçları ve Tartışma}

\section{Çekme Testi Sonuçları}

Çekme testinde tüm malzemeler çekme cihazının çeneleri arasında koparılmıştır. AISI 1008 ve AISI 4140 malzemelerinde boyun verme AISI 1040 malzemesine göre daha fazla gözlemlenmiştir (Şekil 1).

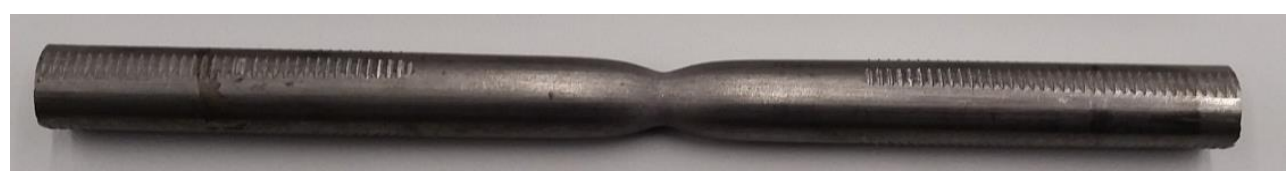

(a)

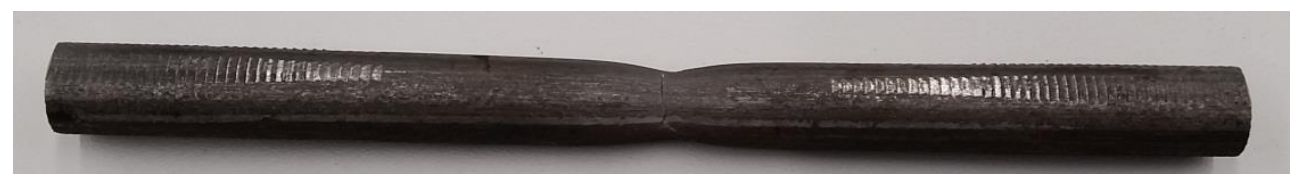

(b)

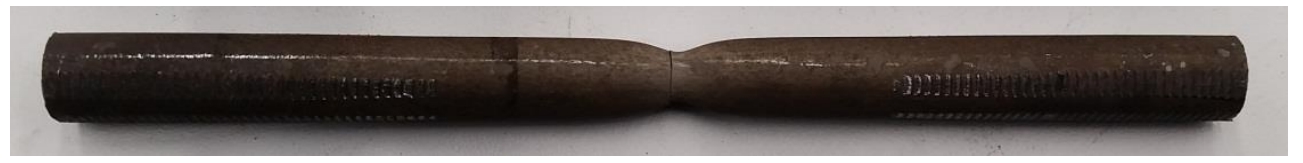

(c)

Şekil 1. Çekme testi sonrası hasara uğrayan numuneler (a: AISI 1008, b: AISI

$$
\text { 1040, c: AISI 4140) }
$$

Şekil 2'de görüldüğü gibi tüm malzemelerde sünek kırılma yüzeyi oluşmuştur. Instron 8803 tek eksenli servohidrolik test sisteminde gerçekleştirilen çekme testi sonuçları Tablo 3 ve Grafik 1'de sunulmuştur. 


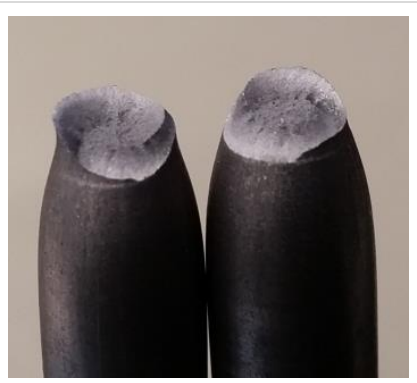

a)

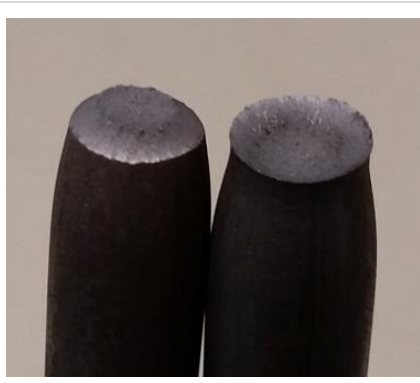

b)

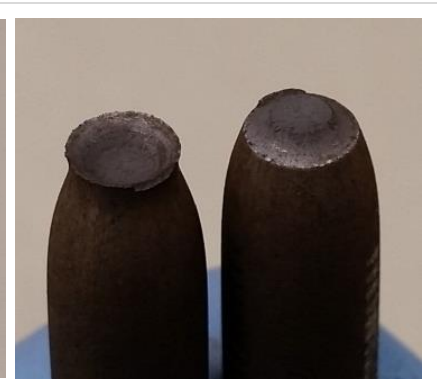

c)

Şekil 2. Çekme testi sonrası kopan yüzeylerin görünümü (a: AISI 1008, b: AISI 1040, c: AISI 4140)

Tablo 3. Malzemelerin çekme dayanımı değerleri

\begin{tabular}{lllll}
\hline \multirow{2}{*}{ ÖZLLIK } & \multicolumn{4}{c}{ MALZEME } \\
\cline { 2 - 5 } Akma Gerilmesi & Numune No. & AISI 1008 & AISI 1040 & AISI 4140 \\
(MPa) & 1 & 357 & 350 & 411 \\
& 2 & 389 & 346 & 387 \\
& 3 & 379 & 343 & 393 \\
Çekme Gerilmesi & Ortalama & $\mathbf{3 7 5 , 0 0}$ & $\mathbf{3 4 6 , 3 3}$ & $\mathbf{3 9 7 , 0 0}$ \\
(MPa) & 1 & 576 & 751 & 734 \\
& 2 & 577 & 743 & 735 \\
& 3 & 573 & 748 & 740 \\
\% Uzama & Ortalama & $\mathbf{5 7 5 , 3 3}$ & $\mathbf{7 4 7 , 3 3}$ & $\mathbf{7 3 6 , 3 3}$ \\
& 1 & 7,91 & 13,04 & 11,68 \\
& 2 & 7,85 & 12,94 & 11,56 \\
& 3 & 7,63 & 12,92 & 11,50 \\
\% Kesit & Ortalama & $\mathbf{7 , 8 0}$ & $\mathbf{1 2 , 9 7}$ & $\mathbf{1 1 , 5 8}$ \\
Daralması & 1 & 60,13 & 49,23 & 63,14 \\
& 2 & 60,49 & 49,23 & 63,31 \\
& 3 & 60,67 & 49,59 & 64,00 \\
\hline & Ortalama & $\mathbf{6 0 , 4 3}$ & $\mathbf{4 9 , 3 5}$ & $\mathbf{6 3 , 4 8}$ \\
\hline
\end{tabular}


AISI 10081040 ve 4140 Çeliklerinde Isıl İşlem, Karbon Oranı ve Alaşım Elementlerinin Mikroyapı ve Mekanik Özelliklere Etkisinin İncelenmesi

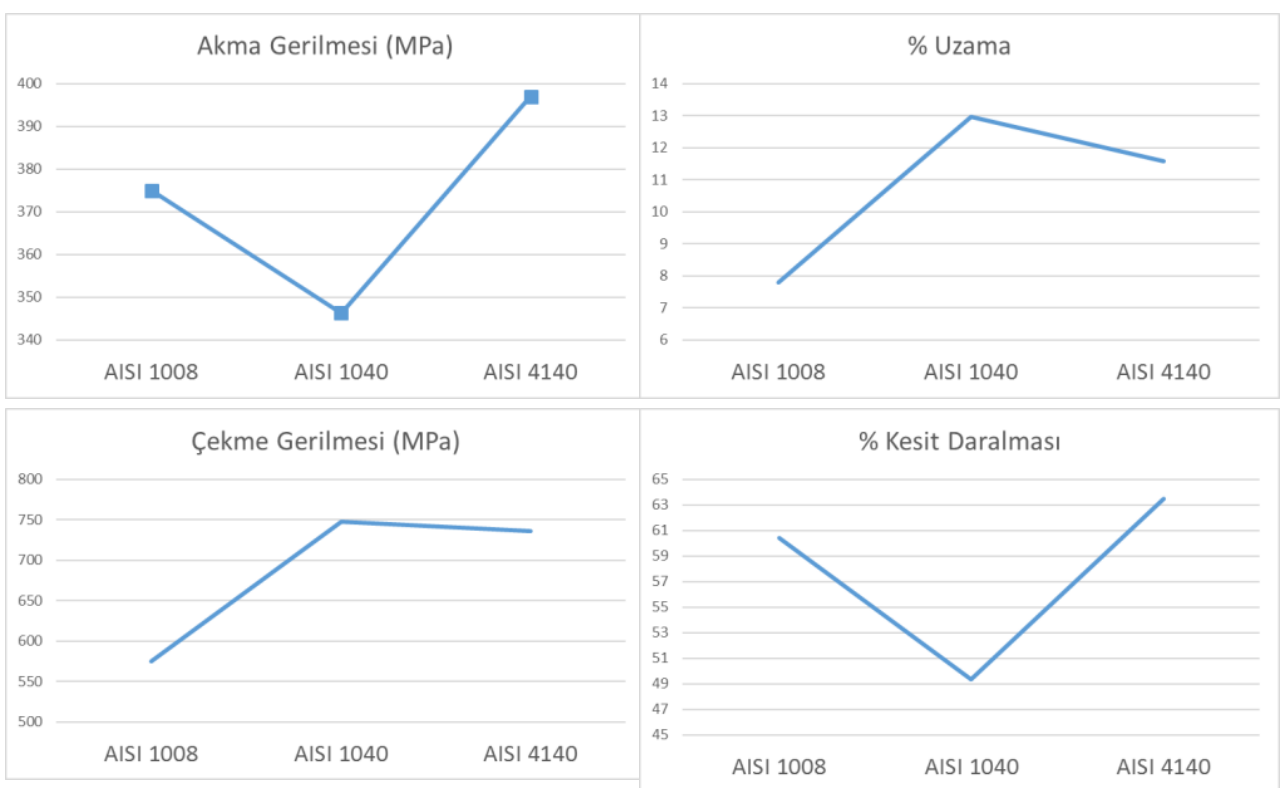

Grafik 1. AISI 1008, 1040 ve 4140 Malzemelerin mekanik özelliklerinin karşıllaştırılması.

Tablo 3 ve Grafik 1'deki akma gerilmesi değerleri incelendiğinde, stok halde alınan üç malzemenin de birbirlerine yakın değerlere sahip olduğu görülmektedir. AISI 1008 malzemesi ortalama $375 \mathrm{MPa}$ akma gerilmesine sahiptir. AISI 1040 malzemesinin AISI 1008 malzemesine göre daha yüksek dayanım vermesi beklenirken yaklaşık $346 \mathrm{MPa}$ değeri ölçülmüsstür. Stok halde bulunan AISI 1040 malzemesine uygulanan 1 s1l işlem sonucunda bu değere sahip olduğu değerlendirilmektedir. AISI 4140 malzemesi ise beklenildiği şekilde diğer iki malzemeye göre daha yüksek değer sunmuş olmasına rağmen, $397 \mathrm{MPa}$ değeri de AISI 4140 için düşük bir değerdir.

Çekme gerilmesi değerleri incelendiğinde ise; orta karbonlu alaşımsız çelik olan AISI 1040 malzemesi, düşük karbonlu alaşımsız çelik olan AISI 1008 malzemesine göre önemli oranda daha yüksek çekme gerilmesi değerine sahiptir. Artan karbon miktarı çekme gerilmesi değerinde önemli ölçüde artışa sebep olmuştur. Aynı karbon oranlarına sahip, alaşımsız AISI 1040 ve alaşımlı AISI 4140 malzemeleri kıyaslanırsa; AISI 4140'1n özellikleri AISI 1040 a göre üstünlük 
gösterebilir. Ancak 1sıl işleme bağlı olarak stok halde bulunan iki malzemenin çekme gerilmesi değerleri birbirlerine yakın sonuç vermiştir.

Karbon oranının artması sonucu, mukavemetin artması ve sünekliğin azalması bilinen bir durumdur. Sonuçlara bakıldığında; AISI 1040 malzemesinin kesit daralmasının beklenildiği gibi AISI 1008 malzemesine göre daha düşük çıktığı görülmektedir. Aynı karbon oranına sahip AISI 1040 ve AISI 4140 malzemeleri kıyaslandığında ise; benzer mukavemet özellikleri göstermelerine rağmen, alaşım elementlerinin etkisi ile AISI 4140 malzemesinin daha sünek olduğu görülmektedir. AISI 4140 malzemesinin uzama değerinde $\% 1,5$ 'ten daha düşük bir azalma varken, kesit daralmasında \%14'ten daha büyük artış gözlemlenmektedir.

Isıl işlemin etkisini görmek için fırın, 150 dakikada $845{ }^{\circ} \mathrm{C}$ sıcaklığa çıkacak şekilde ayarlanmış ve numuneler aynı sıcaklıkta 90 dakika süre bekletilmiş ve havada soğutulmuştur. Isıl işlem uygulanmış numunelerin çekme testi, diğer numuneler ile aynı parametrelerde gerçekleştirilmiş, sonuçlar Grafik 2'de sunulmuştur.

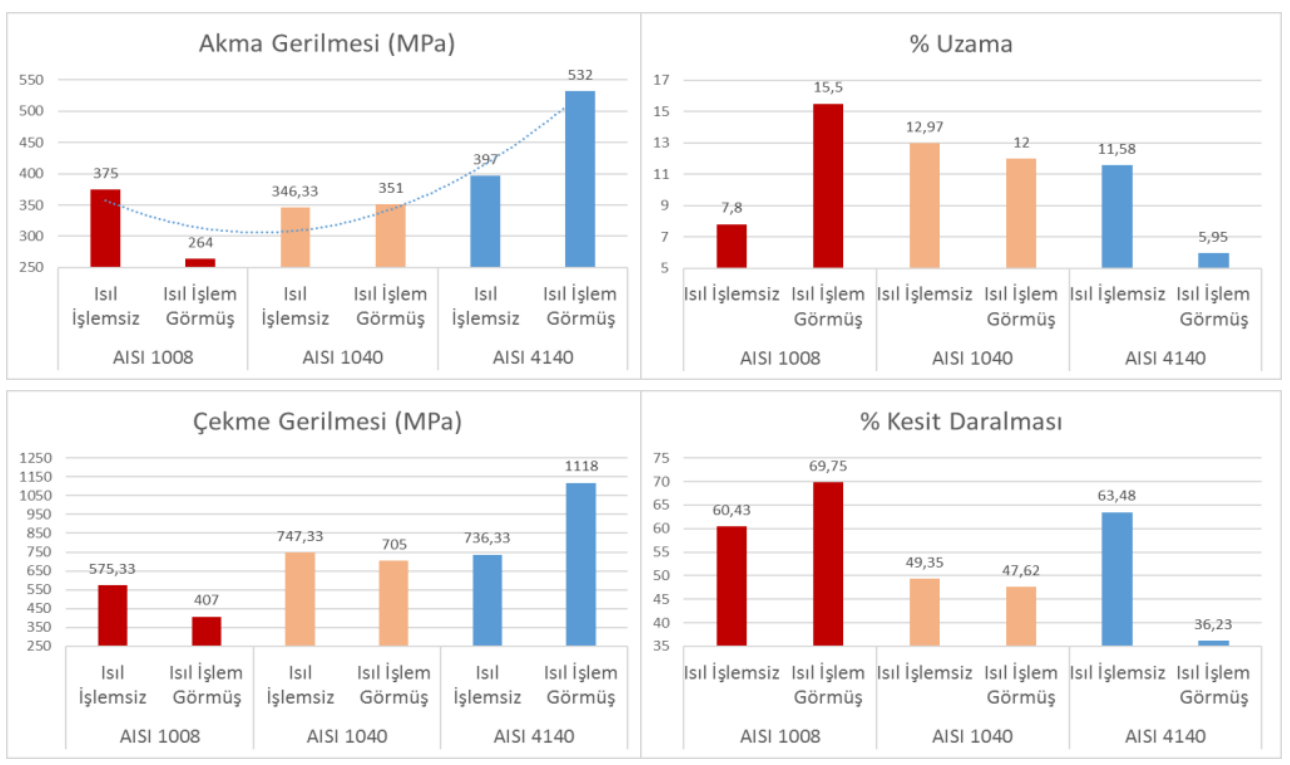

Grafik 2. AISI 1008, 1040 ve 4140 Malzemelerin 1sıl işlem sonras1 mekanik özelliklerinin karşılaştırılması. 
AISI 10081040 ve 4140 Çeliklerinde Isıl İşlem, Karbon Oranı ve

Alaşım Elementlerinin Mikroyapı ve Mekanik Özelliklere Etkisinin İncelenmesi

Test öncesi aynı uzunluğa sahip numunelerin çekme testi sonrası görüntüleri Şekil 3'te gösterilmiştir. Aynı şartlarda 1sıl işleme tabi tutulan malzemelerde, karbon oranı ve alaşım elementlerinin etkileri daha belirgin bir şekilde ortaya çıkmıştır.

Karbon oranının \%0,3 artması ile yaklaşık olarak; akma gerilmesinde \%33 artma, çekme gerilmesinde $\% 73$ artma, uzama değerinde $\% 23$ düşme, kesit daralması değerinde \% 32 düşme ortaya çıkmıştır. Tablo 2'de gösterilen alaşım elementlerinin etkisi ile yaklaşık olarak; akma gerilmesinde \%52 artma, çekme gerilmesinde $\% 59$ artma, uzama değerinde $\% 50$ düşme, kesit daralması değerinde \% 24 düşme ortaya çıkmıştır. AISI 1008, 1040 ve 4140 malzemeleri arasında sonuçlara bakıldığında; karbon oranı, çekme dayanımında ve \% kesit daralmasında daha etkili iken, alaşım elementleri, akma dayanımı ve \% uzamada daha etkili olduğu söylenebilir.

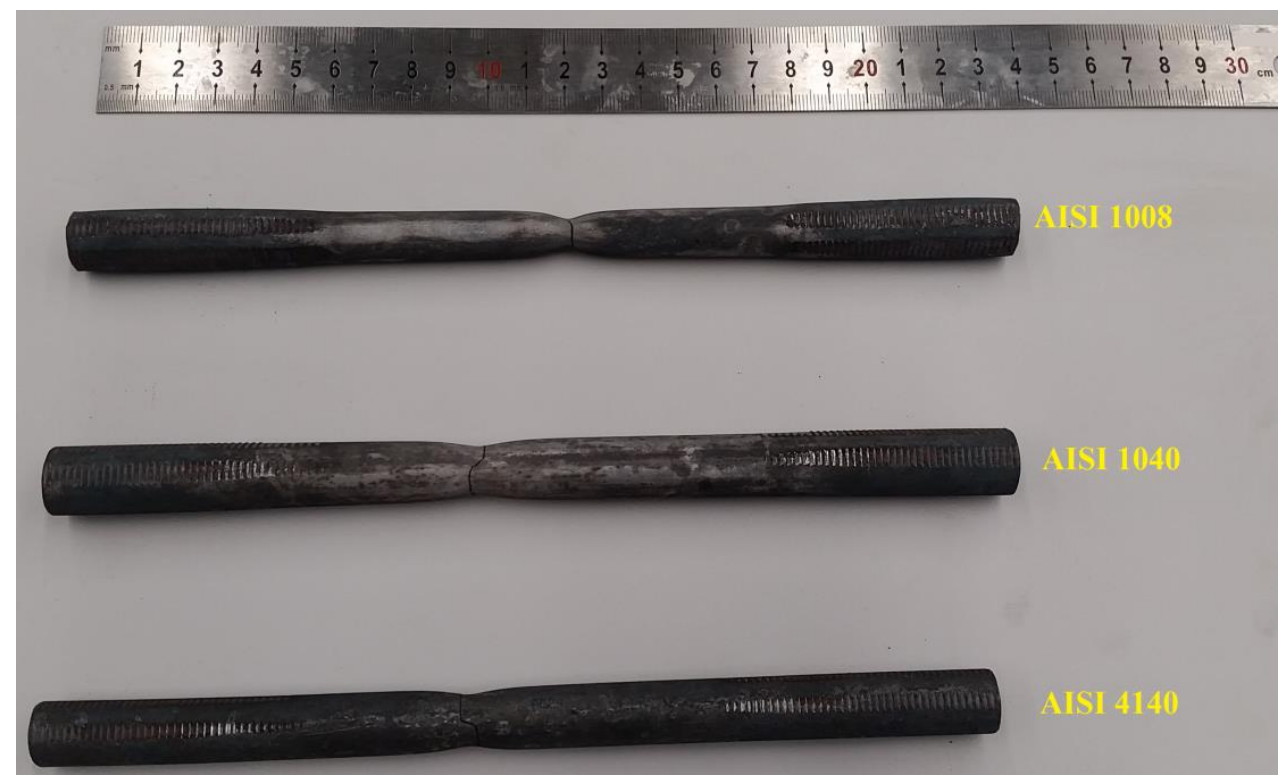

Şekil 3: Isıl işlem sonrası çekme testi numuneleri 


\section{Sertlik Testi Sonuçları}

İçyapı incelemeleri tamamlanan numuneler görüntü alınan yüzeylerden rastgele olacak şekilde 7 ayrı ölçüm yapılmış, bu ölçümlerin en düşük ve en yüksek değerleri dikkate alınmaksızın kalan 5 ölçümün ortalamaları bulunmuştur. Qness Q10 mikrosertlik cihazında malzemelerin sertlik ölçümleri Vickers olarak (HV) elde edilmiştir. $\mathrm{Bu}$ değerler sertlik dönüşüm tablolarından yararlanılarak Brinell sertlik değerine (HB) dönüştürülmüştür. Ayrıca malzemelerin çekme gerilmesi $\left(\sigma_{c}\right)$ değerleri, Brinell sertlik değerlerine bölünerek " $\sigma_{c} / \mathrm{HB}$ ” oranları hesaplanmıştır. Sonuçlar Tablo 4'te, sunulmuştur.

Tablo 4. Malzemelerin sertlik değerleri

\begin{tabular}{cccc}
\hline Malzeme & $\begin{array}{c}\text { AISI } \\
\mathbf{1 0 0 8}\end{array}$ & AISI 1040 & AISI 4140 \\
& 190 & 234 & 224 \\
\hline Ölçüm 1 (HV) & 205 & 238 & 227 \\
\hline Ölçüm 2 (HV) & 197,5 & 236 & 225,5 \\
\hline Ortalama Sertlik (HV) & 187,5 & 224 & 214,5 \\
\hline Ortalama Sertlik (HB) & 3,07 & 3,34 & 3,43 \\
\hline $\boldsymbol{\sigma}_{\mathbf{c}}(\mathbf{M P a}) /$ Sertlik $(\mathbf{H B})$ & & & \\
\hline
\end{tabular}

Sertlik değerleri incelendiğinde; üç malzemenin sertlik değerlerinin beklenildiği gibi çekme gerilmesindeki artışa benzer sırasıyla yükselen değerlere sahip olduğu görülmüştür. Literatürde yaklaşık olarak "Çekme Gerilmesi (MPa) = 3,45 Brinell Sertlik Değeri (HB)" eşitliği vardır (Callister, 2008). AISI 4140 malzemesi bu değere çok yakın sonuç vermiştir.

\section{Mikroyapı İncelemesi}

Üç farklı malzemeye ait 100X ve 1000X büyütmelerdeki mikroyapı görüntüleri Şekil 4’te sunulmuştur. 
AISI 10081040 ve 4140 Çeliklerinde Isıl İşlem, Karbon Oranı ve

Alaşım Elementlerinin Mikroyapı ve Mekanik Özelliklere Etkisinin İncelenmesi

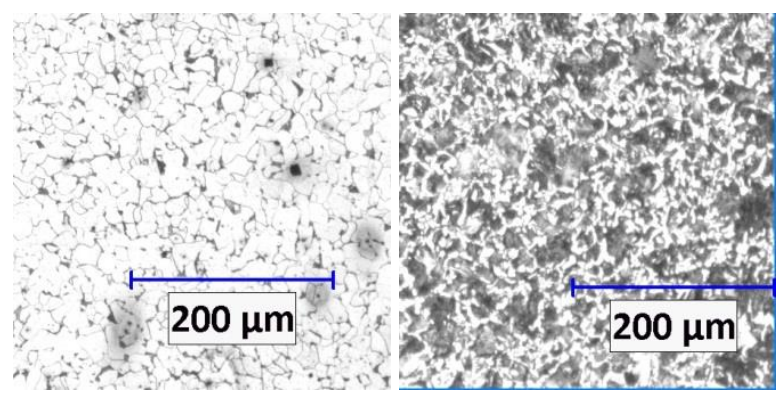

(a)

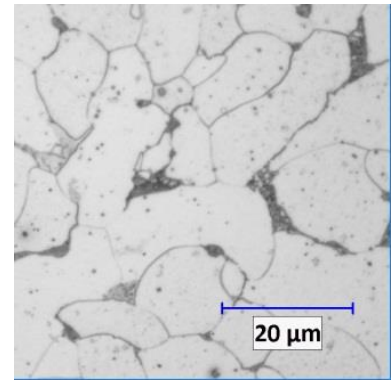

(d) (b)

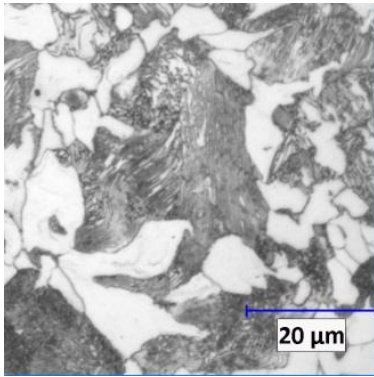

(e)

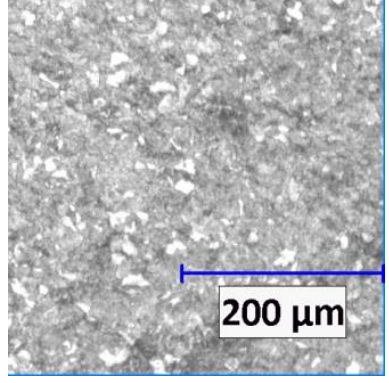

(c)

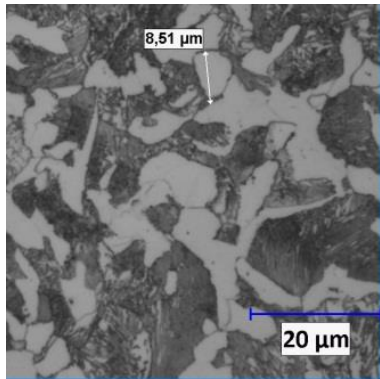

(f)

Şekil 4. AISI 1008, 1040, 4140 çeliklerine ait $100 \mathrm{X}$ ve $1000 \mathrm{X}$ büyütmelerde mikroyapı görüntüleri (a:1008 100X, b:1040 100X, c:4140 100X, d:1008 1000X, e:1040 1000X, f:4140 1000X)

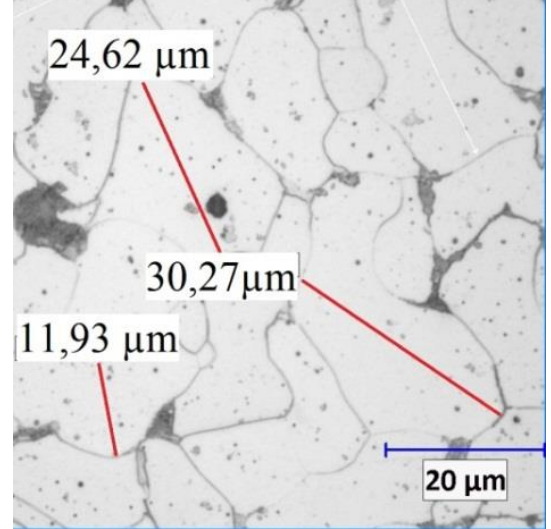

(a)

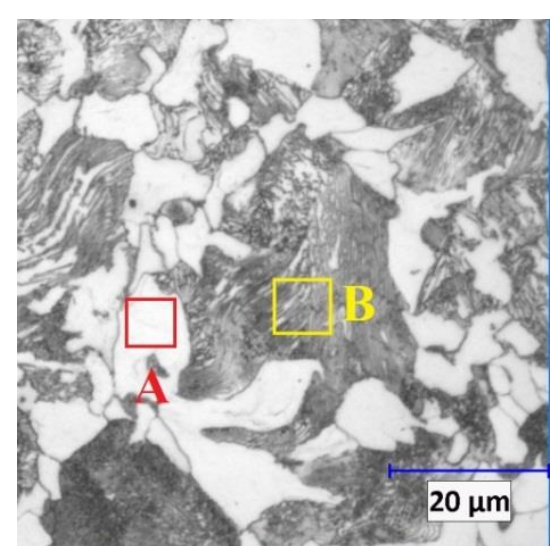

(b)

Şekil 5. AISI 1008 ve 1040 çeliklerine ait 1000X büyütmelerde mikroyap1 görüntüleri (a:1008 1000X, b:1040 1000X) 
Şekil 5 - a incelendiğinde; az karbonlu çeliklerde beklenildiği gibi AISI 1008 malzemesinde Ferritik yapının (beyaz renkli kısımlar) hâkim olduğu görülmektedir. Tane boyutlarına bakıldığında ayrıtlar ortalama $20 \mu \mathrm{m}$ civarındadır. Orta karbonlu AISI 1040 malzemesinin görüntüsü incelendiğinde ise (Şekil 5 - b), A bölümü ile gösterilen bölgede Ferritik yapı, B bölümü ile gösterilen bölgede ise Perlitik yapı görülmektedir. Artan karbon ile birlikte Ferritik yapının bir kısmı Perlitik yapıya dönüşmüştür. AISI 1008 ile kıyaslandığında tane boyutlarında küçülme görülmektedir.

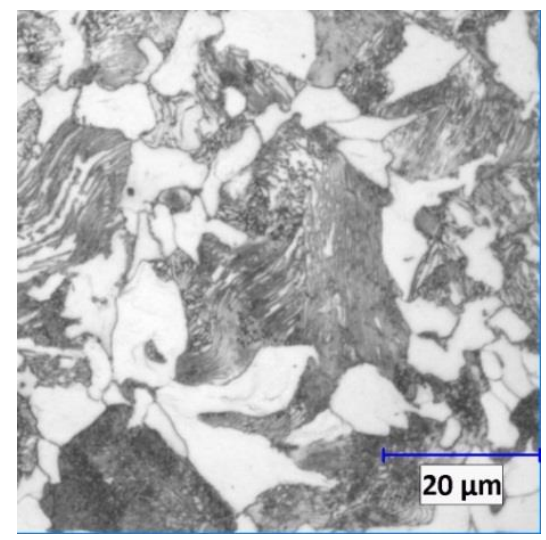

(a)

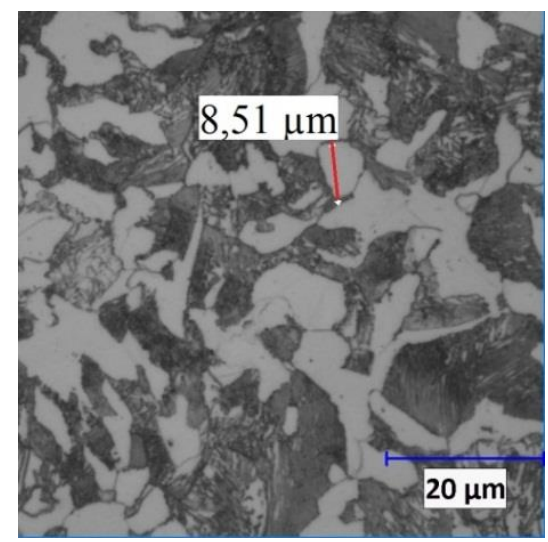

(b)

Şekil 6. AISI 1040 ve 4140 çeliklerine ait $1000 \mathrm{X}$ büyütmelerde mikroyap1 görüntüleri (a:1040 1000X, b:4140 1000X)

Şekil 6'da a ve b görüntüleri incelendiğinde; AISI 4140 malzemesinin tane boyutlarının AISI 1040 malzemesine göre biraz daha küçüldüğü görülmektedir. İki malzemede de benzer mikroyapılar mevcuttur.

\section{Sonuçlar}

AISI 1008, 1040 ve 4140 malzemelerinden numuneler hazırlanmış, 1sıl işlem, çekme testi, sertlik ölçümü ve yüzey görüntüleme işlemleri başarılı bir şekilde uygulanmış sonuçlar aşağıda sunulmuştur. 
AISI 10081040 ve 4140 Çeliklerinde Isıl İşlem, Karbon Oranı ve

1. Stok halde bulunan malzemeler için; daha önce uygulanmış 1sıl işlemler bilinmediğinden, tahmin edilen mekanik özellikler gerçek değerlerinden farklılık gösterebilmektedir.

2. Doğru uygulanmış bir ısıl işlem sonrasında mekanik özellikler önemli ölçüde değişmektedir.

3. Karbon oranının artması sonucu, mukavemetin artması ve sünekliğin azalması bilinen bir durumdur. Sonuçlara bakıldığında; AISI 1040 malzemesinin kesit daralmasının beklenildiği gibi AISI 1008 malzemesine göre daha düşük çıktığı görülmektedir. Aynı karbon oranına sahip AISI 1040 ve AISI 4140 malzemeleri kıyaslandığında ise; benzer mukavemet özellikleri göstermelerine rağmen, alaşım elementlerinin etkisi ile AISI 4140 malzemesinin daha sünek olduğu görülmektedir.

4. Çalışmada karşılaştırılan üç farklı malzeme türü için; karbon oranı, çekme dayanımını ve \% kesit daralmasında daha etkili iken, alaşım elementleri, akma dayanımı ve \% uzama değerlerinde daha etkilidir.

5. Karbon oranının $\% 0,3$ artması ile yaklaşık olarak; akma gerilmesinde $\% 33$ artma, çekme gerilmesinde \%73 artma, uzama değerinde \%23 düşme, kesit daralması değerinde \% 32 düşme ortaya çıkmıştır. Tablo 2 'de gösterilen alaşım elementlerinin etkisi ile yaklaşık olarak; akma gerilmesinde \%52 artma, çekme gerilmesinde $\% 59$ artma, uzama değerinde $\% 50$ düşme, kesit daralması değerinde \% 24 düşme ortaya çıkmıştır. AISI 1008, 1040 ve 4140 malzemeleri arasında sonuçlara bakıldığında; karbon oranı, çekme dayanımını ve \% kesit daralmasında daha etkili iken, alaşım elementleri, akma dayanımı ve \% uzamada daha etkili olduğu gözlemlenmiştir.

6. Çekme gerilmesi ile sertlik arasındaki oran üç malzemede de farklılık göstermektedir.

\section{Extended Summary}

\section{Introduction}

Due to the development of technology, new manufacturing and production technologies are developing and new material designs are emerging through the 
use of these technologies. Mechanical properties are one of the most important factors determining the properties and usage conditions of materials. Mechanical properties have a great advantage in material selection and among the most known ways to improve mechanical properties in steels; increasing the carbon ratio, alloying and heat treatment. There are many studies in the literature on the effects of carbon and other elements on the mechanical properties of steels.

Cast irons and steels known as iron-based alloys are used more than other metals and alloys. Intensive demand for steel and cast iron in the industry; their abundance in the earth, the fact that their production is relatively economical, and perhaps most importantly, their ability to have a wide range of mechanical properties (Callister, 2013). The AISI-4140 steel is the most important feature because it can constitute a hard martensitic structure after quenching heat treatment due to the $\mathrm{Cr}$ and Mo alloying elements it contains and to provide mechanical properties such as strength, ductility and toughness together. For these reasons, the AISI-4140 steel has a widespread use (Avner, 1986: 315-336 and Choo et al., 2000: 56-70).

The basic alloy element of the steels is carbon (C) and shows different properties depending on its composition. Low carbon steels are easy to process and have a ductile structure at the same time. Depending on the amount of carbon, the hardenability increases with quenching, while the machinability decreases. In addition to carbon, other alloying elements in the steel give different mechanical properties to the steel. Alloying elements play an important role in the change of mechanical properties such as tensile strength, yield limit, impact strength, ductility and machinability (Thelning, KE, 1984: 45-93).

The positive effects of alloying elements on the mechanical properties of steel are known (Table 1). Manganese (Mn): It is an element that is involved in the production process of the steel structure and has the effect of increasing the strength of the steel in the positive direction. It also increases hardenability and weldability of the steel. Manganese is a stabilizing element. Chromium (Cr): It is an alloy element that increases resistance and reduces the ductility of the steel. Molybdenum (Mo): It prevents grain growth in the material structure, increases the hardenability and eliminates tempering brittleness. Silisium ( $\mathrm{Si}$ ): It is used as oxygen deactivator. Molybdenum increases the yield of steel, tensile strength and 
AISI 10081040 ve 4140 Çeliklerinde Isıl İşlem, Karbon Oranı ve

ductility. As the amount of silicon in the steel structure decreases, the rate of corrosion increases.

Sulfur (S): It has little effect on yield strength and tensile strength. Despite this, the effect of the material on the percentage of length and toughness is considerably high. It leads to the reduction of toughness and ductility of the material. The maximum amount of sulfur in quality Quenched and Tempered Steels is $0.045 \%$. For prime Quenched and Tempered Steels this ratio is $0,035 \%$. Phosphor (P): it is a kind of element which we do not want to have in the content which creates undesirable effects in the steel. Because of the bad effects on the ductility and toughness of the steel, they are not widely used (http://www.atacelik.com/etkileri.html).

Table 1. Effect of alloy elements on steel (http://www.atacelik.com/ etkileri.html)

\begin{tabular}{lccccccccc}
\hline Properties / Alloying Elements & C & Mn & Si & Cr & Ni & Mo & W & Co & Al \\
\hline Tensile Strength & + & + & + & + & + & + & + & + & + \\
Elongation & $\downarrow$ & $\rightarrow$ & $\downarrow$ & $\downarrow$ & + & $\rightarrow$ & $\downarrow$ & $\downarrow$ & $\downarrow$ \\
Critical Cooling Rate & $\downarrow$ & $\downarrow$ & + & $\downarrow$ & $\downarrow$ & $\rightarrow$ & $\rightarrow$ & $\downarrow$ & $\rightarrow$ \\
Hardness Depth & + & + & + & + & + & + & + & + & $\downarrow$ \\
Strength in Hot & + & + & + & + & + & + & + & + & + \\
Temper strength & $\rightarrow$ & $\rightarrow$ & + & + & $\rightarrow$ & + & + & + & $\rightarrow$ \\
Wear Resistance & + & + & + & + & + & + & + & + & $\rightarrow$ \\
Resistance to scaling & $\downarrow$ & $\rightarrow$ & + & + & + & $\downarrow$ & $\rightarrow$ & + & + \\
Machining & $\downarrow$ & $\downarrow$ & $\downarrow$ & $\downarrow$ & $\downarrow$ & $\downarrow$ & $\downarrow$ & + & $\rightarrow$ \\
Corrosion Durability & $\downarrow$ & $\rightarrow$ & + & + & + & + & $\rightarrow$ & + & + \\
\hline
\end{tabular}

Although much information has been produced up to now, depending on the composition of the steel, the debate about the evolution of the mechanical properties of steel with carbon is still ongoing. 


\section{Material and Method}

\section{Preparation of Samples}

The materials were used directly in the produced diameters to avoid the negative features of the chip removal process. Samples of AISI 1008 at a diameter of $14 \mathrm{~mm}$ material were prepared for tensile testing, hardness measurement and microstructure imaging. Samples of AISI 4140 at a diameter of $16 \mathrm{~mm}$ material were prepared for tensile testing, hardness measurement and microstructure imaging. The chemical compositions of the materials supplied by Ereğli Demir ve Çelik Fab. T.A.Ş. are given in Table 2.

Table 2. Chemical compositions of materials (https://www.erdemir.com.tr)

\begin{tabular}{|c|c|c|c|c|c|c|c|}
\hline Material & $\begin{array}{l}\text { Carbon } \\
\text { (C) }\end{array}$ & $\begin{array}{c}\text { Manganese } \\
(\mathrm{Mn})\end{array}$ & $\begin{array}{l}\text { Phosphor } \\
\text { (P) }\end{array}$ & $\begin{array}{l}\text { Sulfur } \\
(\mathrm{S})\end{array}$ & $\begin{array}{l}\text { Chromium } \\
\text { (Cr) }\end{array}$ & $\begin{array}{c}\text { Molybdenum } \\
\text { (Mo) }\end{array}$ & $\begin{array}{l}\text { Silicon } \\
\text { (Si) }\end{array}$ \\
\hline $\begin{array}{l}\text { AISI } \\
1008\end{array}$ & $0,02-0,1$ & $\leq 0,5$ & $\leq 0,03$ & $\leq 0,035$ & 0,15 & 0,06 & 0,1 \\
\hline $\begin{array}{l}\text { AISI } \\
1040\end{array}$ & $\begin{array}{c}0,37- \\
0,44 \\
\end{array}$ & $0,6-0,9$ & $\leq 0,03$ & $\leq 0,035$ & - & - & $\begin{array}{l}0,15- \\
0,35\end{array}$ \\
\hline $\begin{array}{l}\text { AISI } \\
4140\end{array}$ & $\begin{array}{c}0,38- \\
0,43\end{array}$ & $0,75-1$ & $\leq 0,035$ & $\leq 0,04$ & $0,8-1,1$ & $0,15-0,25$ & $\begin{array}{c}0,15- \\
0,25\end{array}$ \\
\hline
\end{tabular}

Tensile test specimens were subjected to normalization heat treatment. When this application was carried out, the samples annealed at $845{ }^{\circ} \mathrm{C}$ were allowed to cool down in air. In this way, the homogeneities that may have occurred during the production of the materials have been eliminated and the mechanical properties have been improved.

\section{Tensile Test}

The tensile tests of the prepared specimens were carried out in a $500 \mathrm{kN}$ capacity Instron 8803 uniaxial servo hydraulic test system with load control at a rate of $15 \mathrm{kN} / \mathrm{min}$ with 3 samples. The tensile stress, yield stress, \% elongation 
AISI 10081040 ve 4140 Çeliklerinde Isıl İşlem, Karbon Oranı ve

values and \% section contraction values of the materials were determined using the tensile test device. The averages of the obtained values were calculated.

\section{Hardness Measurement}

The hardness measurements of the samples were carried out on a Qness Q10 micro hardness tester using the micro Vickers method. Test parameters HV0.5 load, 10 seconds main load values were determined, trace images were taken with $40 \mathrm{X}$ lens.

\section{Microstructure Analysis}

Samples of $15 \mathrm{~mm}$ thickness were cut from 3 different materials, hot bakalite mold was taken. Then sanding and polishing were done. Afterwards, Nital3 chemistry was used to carry out etching processes. Microstructure images of the prepared samples were taken at 100X, 200X, 500X and 1000X magnifications with Nikon MA200 Light microscope.

\section{Test Results and Discussion}

\section{Tensile Test Results}

In the tensile test, all materials were broken between the blades of the tensile test device. In AISI 1008 and AISI 4140 materials necking was more observed than in AISI 1040 material (Figure 1).

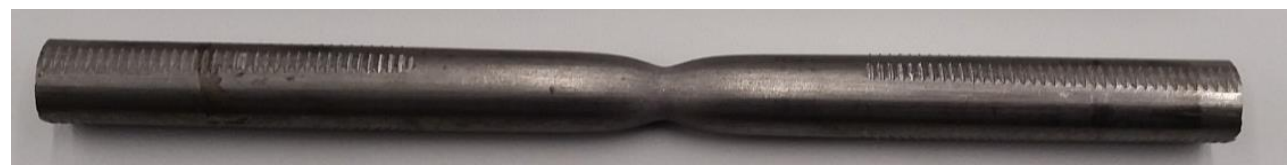

(a)

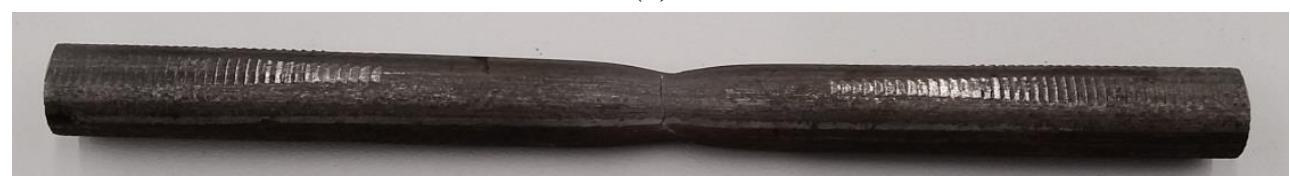

(b) 


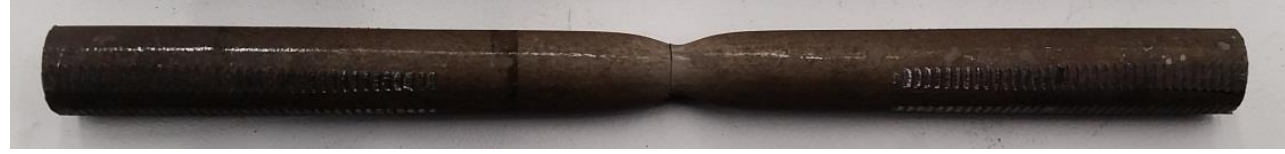

(c)

Figure 1. Broken samples after tensile test (a: AISI 1008, b: AISI 1040, c: AISI 4140)

Table 3. Mechanical properties of materials

\begin{tabular}{|c|c|c|c|c|}
\hline \multirow{2}{*}{ PROPERTIES } & \multicolumn{4}{|c|}{ MATERIAL } \\
\hline & Specimen & AISI 1008 & AISI 1040 & AISI 4140 \\
\hline \multirow{4}{*}{$\begin{array}{l}\text { Yield Stress } \\
\text { (MPa) }\end{array}$} & 1 & 357 & 350 & 411 \\
\hline & 2 & 389 & 346 & 387 \\
\hline & 3 & 379 & 343 & 393 \\
\hline & Average & 375,00 & 346,33 & 397,00 \\
\hline \multirow{4}{*}{$\begin{array}{l}\text { Tensile Stress } \\
\text { (MPa) }\end{array}$} & 1 & 576 & 751 & 734 \\
\hline & 2 & 577 & 743 & 735 \\
\hline & 3 & 573 & 748 & 740 \\
\hline & Average & 575,33 & 747,33 & 736,33 \\
\hline \multirow{4}{*}{$\%$ Elongation } & 1 & 7,91 & 13,04 & 11,68 \\
\hline & 2 & 7,85 & 12,94 & 11,56 \\
\hline & 3 & 7,63 & 12,92 & 11,50 \\
\hline & Average & 7,80 & 12,97 & 11,58 \\
\hline \multirow{4}{*}{$\begin{array}{l}\% \text { Section } \\
\text { Contraction }\end{array}$} & 1 & 60,13 & 49,23 & 63,14 \\
\hline & 2 & 60,49 & 49,23 & 63,31 \\
\hline & 3 & 60,67 & 49,59 & 64,00 \\
\hline & Average & 60,43 & 49,35 & 63,48 \\
\hline
\end{tabular}


AISI 10081040 ve 4140 Çeliklerinde Isıl İşlem, Karbon Oranı ve
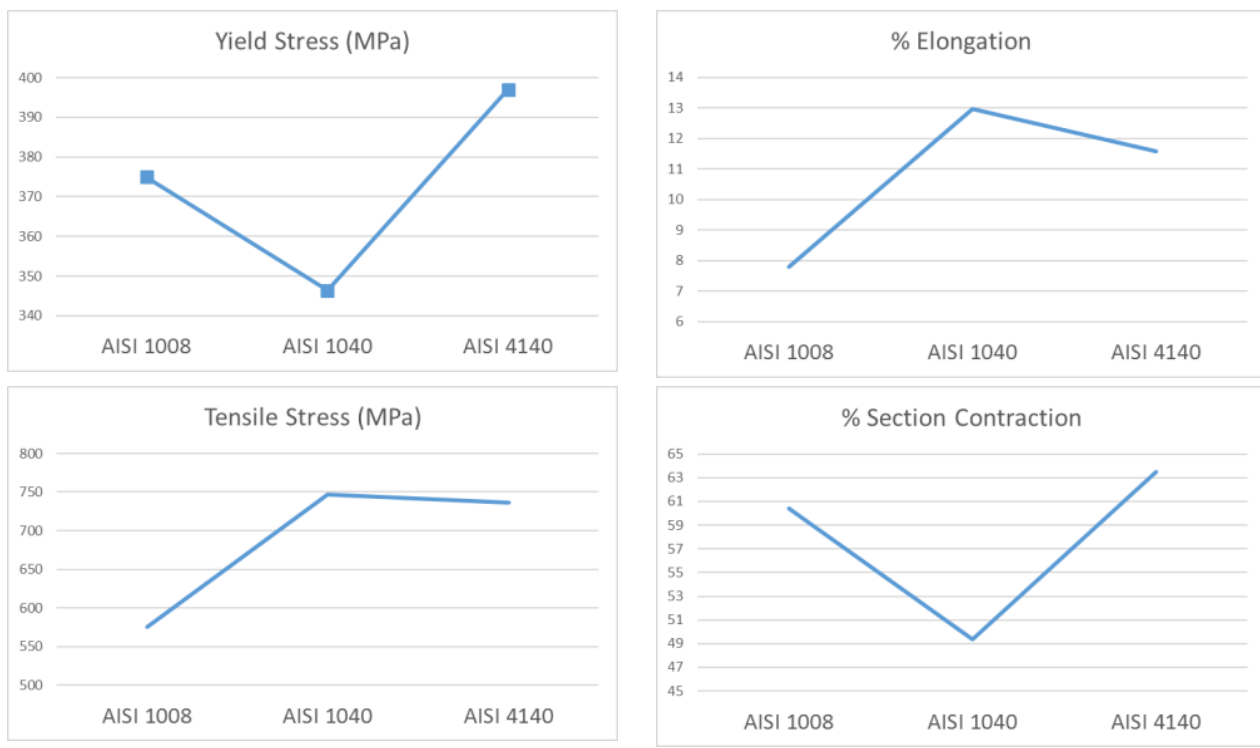

Graph 1. Comparison of mechanical properties of AISI 1008, 1040 and 4140 Materials

When the yield stress values in Table 3 and Graph 1 are examined, it is seen that the three materials taken in stock have similar values to each other. The AISI 1008 material has an average yield stress of $375 \mathrm{MPa}$. The AISI 1040 material was expected to give higher strength than the AISI 1008 material, and was measured at about $346 \mathrm{MPa}$. It is estimated that this value is the result of the heat treatment applied to the stock AISI 1040 material. The AISI 4140 material, as expected, offers a higher value than the other two materials, but the $397 \mathrm{MPa}$ is a low value for the AISI 4140.

The increased amount of carbon has caused a significant increase in the tensile strength value. It is a well-known fact that the increase in the carbon ratio results in increased strength and reduced ductility. According to the results; AISI 1040 material \% section contraction is lower than that of AISI 1008 material as expected.

To see the effect of heat treatment, the samples prepared from three different materials were heated to $845^{\circ} \mathrm{C}$ in 150 minutes, kept at the same temperature for 90 minutes and cooled in air. The tensile test of the heat treated 
samples was carried out in the same parameters as the other samples and the results are presented in Graph 2.

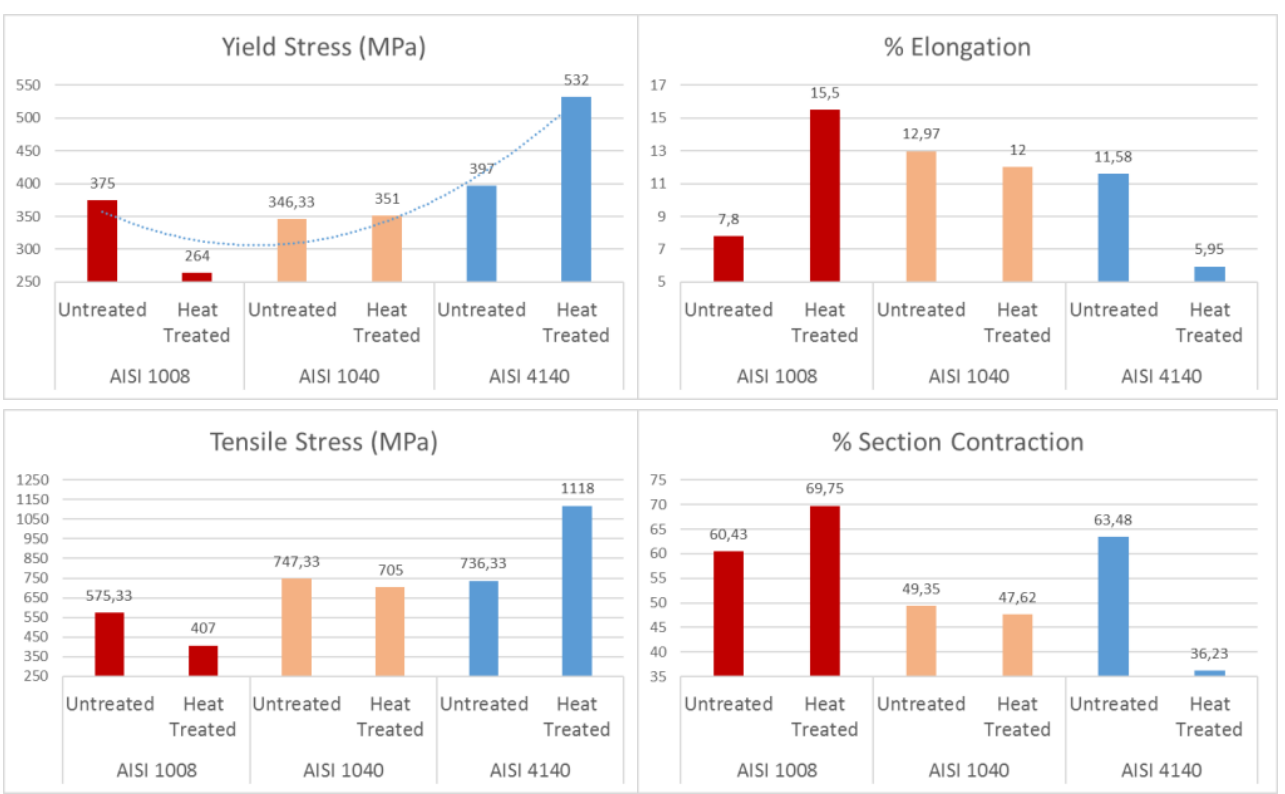

Graphic 2. Comparison of mechanical properties of AISI 1008, 1040 and 4140 materials after heat treatment

Approximately with a $0.3 \%$ increase in carbon content; a $33 \%$ increase in yield stress, a $73 \%$ increase in tensile stress, a $23 \%$ decrease in elongation value, and a $32 \%$ decrease in section contraction value. Approximately by the effect of the alloying elements shown in Table 2; 52\% increase in yield stress, 59\% increase in tensile stress, $50 \%$ decrease in elongation value, $24 \%$ decrease in section contraction value. When looking at the results between AISI 1008, 1040 and 4140 materials; carbon ratio is more effective in tensile strength and \% section contraction, while alloying elements are more effective in yield strength and\% elongation. 
AISI 10081040 ve 4140 Çeliklerinde Isıl İşlem, Karbon Oranı ve

Alaşım Elementlerinin Mikroyapı ve Mekanik Özelliklere Etkisinin İncelenmesi

\section{Hardness Test Results}

Randomly 7 measurements were made after investigation of the microstructure, and the average of the remaining 5 measurements was found regardless of the lowest and highest values of these measurements. The hardness measurements of the materials in the Qness Q10 micro hardness machine were obtained as Vickers (HV). These values were converted to Brinell hardness value (HB) using hardness conversion tables. In addition, the tensile strength $\left(\sigma_{t}\right)$ values of the materials were divided by the Brinell hardness values and the " $\sigma_{\mathrm{t}} / \mathrm{HB}$ " ratios were calculated. The results are presented in Table 4.

Table 4. Hardness values of materials

\begin{tabular}{cccc}
\hline Material & AISI 1008 & AISI 1040 & AISI 4140 \\
\hline Measurement 1 $(\mathbf{H V})$ & 190 & 234 & 224 \\
Measurement 2 $(\mathbf{H V})$ & 205 & 238 & 227 \\
Average Hardness $(\mathbf{H V})$ & 197,5 & 236 & 225,5 \\
\hline Average Hardness $(\mathbf{H B})$ & 187,5 & 224 & 214,5 \\
$\boldsymbol{\sigma}_{\mathbf{t}}(\mathbf{M P a})$ / Hardness $(\mathbf{H B})$ & 3,07 & 3,34 & 3,43 \\
\hline
\end{tabular}

When the hardness values are examined; the hardness values of the three materials were found to be proportional to the tensile stress as expected. In the literature there is an approximation of "Tensile Strength $(\mathrm{MPa})=3.45$ Brinell Hardness Value (HB)" (Callister, 2008). The AISI 4140 material yielded very close results.

\section{Microstructure Analysis}

Microstructure images at $100 \mathrm{X}$ and $1000 \mathrm{X}$ magnifications of three different materials are presented in Fig. 2. 


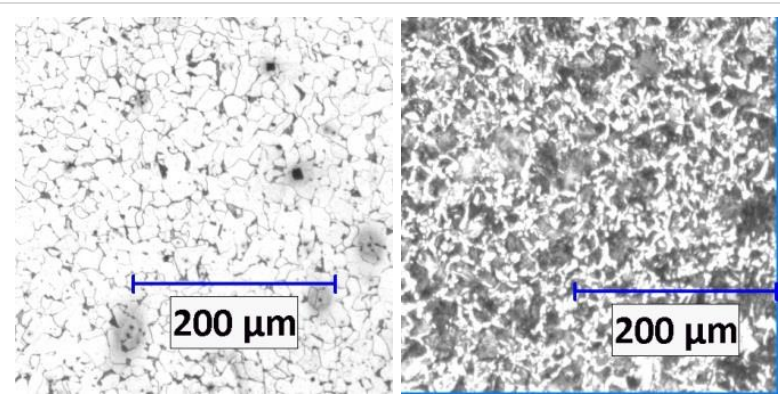

(a)

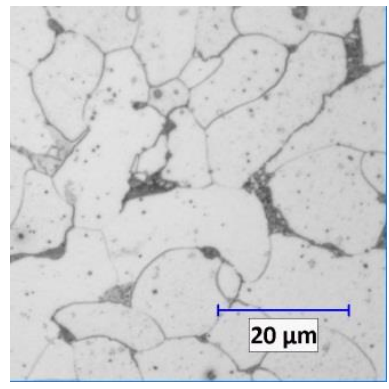

(d) (b)

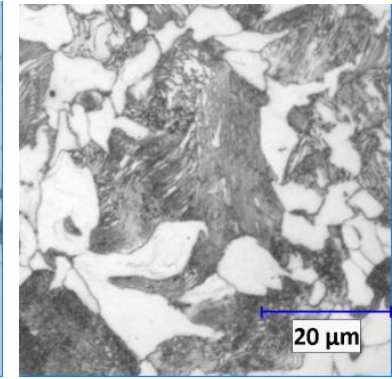

(e)

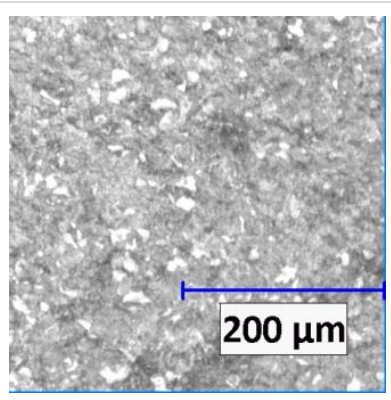

(c)

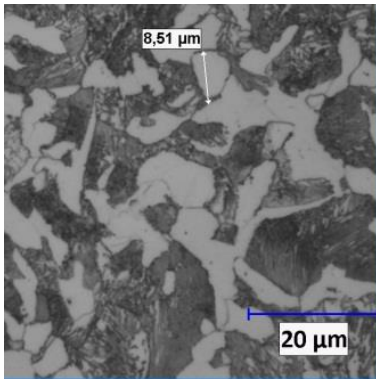

(f)

Figure 2. Microstructure images at 100X and 1000X magnifications of AISI 1008, 1040, 4140 steels, respectively. (a:1008 100X, b:1040 100X, c:4140 100X, d:1008 1000X, e:1040 1000X, f:4140 1000X)

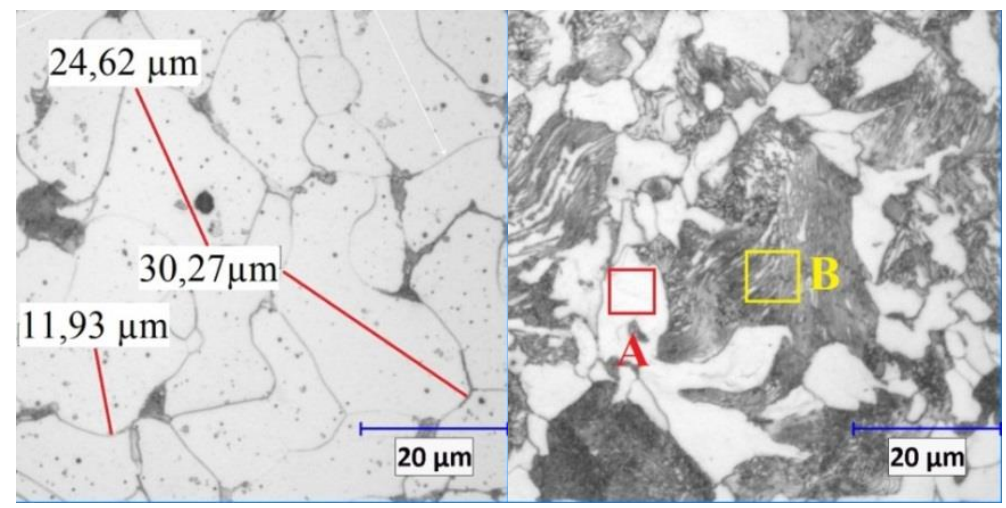

(a)

(b)

Figure 3. Microstructure images at 1000X magnifications of AISI 1008 and 1040 steels (a:1008 1000X, b:1040 1000X) 


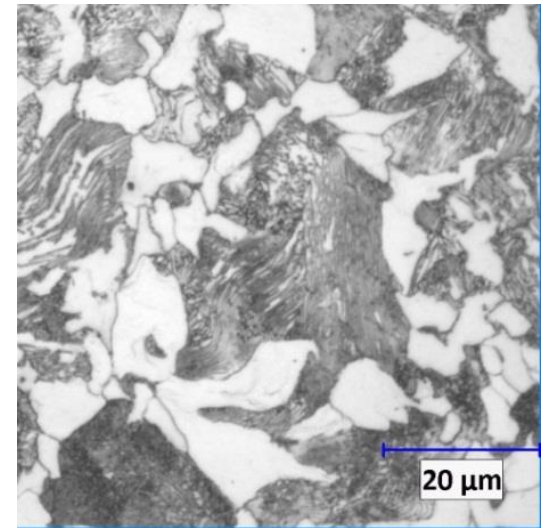

(a)

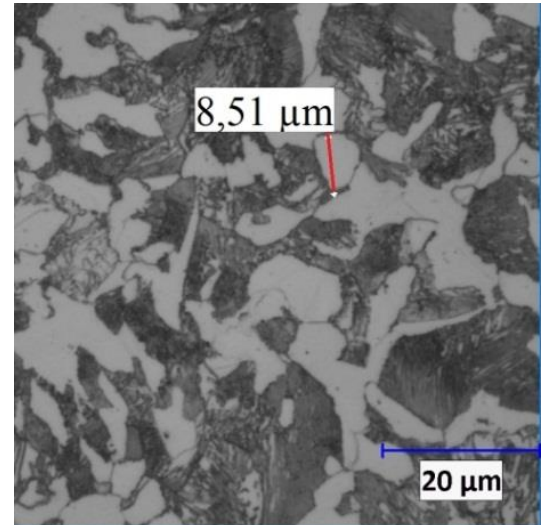

(b)

Figure 4. Microstructure images at 1000X magnifications of AISI 1040 and 4140 steels (a:1040 1000X, b:4140 1000X)

When the images $\mathrm{a}$ and $\mathrm{b}$ are examined in Fig 3 and Fig. 4, it is seen that the grain sizes of AISI 4140 material are slightly smaller than those of AISI 1040 material. Similar microstructures are present in both materials.

\section{Results}

Samples of AISI 1008, 1040 and 4140 materials were prepared, heat treatment, tensile test, hardness measurement and surface imaging were successfully applied. The results obtained are presented below.

1. For materials in stock; Since previously applied heat treatments are not known, the predicted mechanical properties may differ from their actual values.

2. Mechanical properties vary considerably after a correctly applied heat treatment.

3. It is a well-known fact that the increase in the carbon ratio results in increased strength and reduced ductility. According to the results; AISI 1040 material section contraction is lower than that of AISI 1008 material as expected. When the AISI 1040 and AISI 4140 materials with the same carbon content are 
compared, it is seen that AISI 4140 material is more ductile with the effect of alloy elements, although they show similar strength properties.

4. For three different types of materials compared in the study; carbon ratio is more effective in tensile strength and \% section contraction, while alloying elements are more effective in yield strength and elongation values.

5. Approximately with a $0.3 \%$ increase in carbon content; a $33 \%$ increase in yield stress, a $73 \%$ increase in tensile stress, a $23 \%$ decrease in elongation value, and a $32 \%$ decrease in section contraction value. Approximately by the effect of the alloying elements shown in Table 2; 52\% increase in yield stress, 59\% increase in tensile stress, $50 \%$ decrease in elongation value, $24 \%$ decrease in section contraction value. When looking at the results between AISI 1008, 1040 and 4140 materials; carbon ratio is more effective in tensile strength and \% section contraction, while alloying elements are more effective in yield strength and \% elongation.

6. The ratio between tensile stress and hardness also varies in the three materials.

\section{Kaynakça}

\section{Kitaplar}

Avner, S.H. (1986) Introduction to Physical Metallurgy, McGraw Hill Book Company, 2.ed., New York, 315-336.

Callister, W. D., \& Rethwisch, D. G. (2008) Fundamentals of materials science and engineering: An integrated approach. Hoboken, NJ: John Wiley \& Sons.

Krauss, George \& Grossmann, M. A. (Marcus Aurelius), (1980) Principles of heat treatment of steel. American Society for Metals, Metals Park, Ohio.

Lorusso, H., (2009) Soldadura de aceros dual phase en chapa fina: obtención, procesos, microestructuras y propiedades mecánicas. Universidad de Buenos Aires.

Parrish, Geoffrey (1980) The influence of microstructure on the properties of casecarburized components. American Society for Metals, Metals Park, Ohio. 
AISI 10081040 ve 4140 Çeliklerinde Isıl İşlem, Karbon Oranı ve

Thelning, K-E., (1984) Steel and Its Heat Treatment (2nd Ed.), Butterworths, London, UK., 45-93.

\section{Makaleler}

Choo, Seong-Hun \& Lee, Sunghak \& Golkovsky, M.G.. (2000). Effects of accelerated electron beam irradiation on surface hardening and fatigue properties in an AISI 4140 steel used for automotive crankshaft. Materials Science and Engineering A-structural Materials Properties Microstructure and Processing - MATER SCI ENG A-STRUCT MATER. 293:56-70. https://doi.org/10.1016/S0921-5093(00)01207-7.

Maffei, B., Salvatore, W., Valentini, R., (2007) Dual-phase steels rebars for highductile r.c. structures, part I: microstructural and mechanical characterization of steel rebars. Engineering Structures Vol. 29: 33253332 .

Svoboda; H., Lorusso, H.N., Burgueño, A., (2011) Soldadura de aceros Dual Phase en chapa fina: GMAW, PAW y RSW Soldag. insp. São Paulo, Vol.16, No. 2, p.165-176.

Valeria L. de la Concepcióna , Hernán N. Lorussoa,b, Hernán G. Svobodab,c (2015) Effect of carbon content on microstructure and mechanical properties of dual phase steels, Procedia Materials Science 8: 1047-1056 https://doi.org/10.1016/j.mspro.2015.04.167

\section{Web Siteleri}

Çeliğe Alaşım Elementlerinin Etkileri. 13 Mart 2018'de http://www.atacelik.com/etkileri.htm adresinden erişim sağlanmıştır.

Material Property Datai. 15 Mart 2018'de, 05 Ekim 2018'de (https://www.erdemir.com.tr/Sites/1/upload/files/web.tr-2500.pdf) adresinden erişim sağlanmıştır. 